\title{
Spatial Spillover Effects of Financial Development on Regional Ocean Economy Growth of China Based on SDM
}

\author{
Jianyue Ji*, Huiwen Guo, Weilong Wang \\ School of Economics, Ocean University of China, Qingdao, China \\ Email address: \\ jijianyue@163.com (Jianyue Ji),oucghw@163.com (Huiwen Guo),727902012@qq.com (Weilong Wang) \\ ${ }^{*}$ Corresponding author
}

\section{To cite this article:}

Jianyue Ji, Huiwen Guo, Weilong Wang. Spatial Spillover Effects of Financial Development on Regional Ocean Economy Growth of China Based on SDM. International Journal of Economics, Finance and Management Sciences. Vol. 6, No. 3, 2018, pp. 110-117. doi: $10.11648 /$ j.ijefm.20180603.16

Received: April 20, 2018; Accepted: June 12, 2018; Published: June 20, 2018

\begin{abstract}
Based on partial differential analysis of Spatial Durbin Model (SDM), this paper selects provincial panel data of 11 coastal provinces in China from 2006 to 2014 to empirically study the spatial spillover effects of financial development on regional marine economy. The results show that there are significant spatial correlations in China's marine economy, and it is manifested as spatial exclusion, that is, there is a certain "congestion effect". At this stage, Financial Interrelations Ratio (FIR) and Venture Capital (VC) have positive direct effects and negative spatial spillover effects on the development of marine economy. Government investment, on the contrary, has a negative direct effect and a positive spatial spillover effect on it. The impact of insurance on the marine economy is not significant.
\end{abstract}

Keywords: Marine Economy, Financial Development, Panel SDM, Spatial Spillover Effects

\section{Introduction}

As the world's population continues to grow, the shortage of land resources, energy, and the shrink of development space is becoming more and more serious. The rational development of marine resources and marine economy are of great significance to the sustainable and coordinated development of human society, economy and ecological environment in the 21st century. The ocean is rich in resources and space. Exploiting and utilizing marine resources is one of the important ways to solve the three major problems facing humanity: population, resources, and the environment. [1] It is also the material basis for the development and progress of human society. [2] China's government proposed to "adhere to overall planning of land and ocean, and speed up the construction of marine power." The importance of developing marine economy to China's economic growth is becoming more and more obvious.

In recent years, China's marine economy has achieved considerable development. According to China Marine Economic Statistics Bulletin of 2017, the Gross Ocean Product (GOP) in 2017 was 7.7611 trillion yuan with an increase of $6.9 \%$ over the previous year, accounting for $9.4 \%$ of GDP. By region, the GOP in the Bohai Rim Region accounts for $31.7 \%$ of the country's total, 29.6\% in the Yangtze River Delta region, and $23.4 \%$ in the Pearl River Delta Region. Marine economic development has a large space and strong potential. It is gradually becoming a new growth point for regional economic development and has played a significant role in the national economy.

The modern marine economy is characterized by technology-intensive, risk-intensive and capital-intensive, among which the need for funds is particularly strong. [3] However, with the continuous development of China's marine economy and the optimization of its industrial structure, the shortage of funds has restricted the sustained and stable growth of China's marine economy. [4] The marine industry itself is characterized by high risk, long payback period, and strong professional and technical characteristics. Therefore, it is difficult for commercial banks and other traditional financing channels to assess their investment returns and risks, thus cannot meet financing needs of marine economy. In addition, China's current marine finance is still incomplete and lacks specialized financial institutions. [5] This phenomenon objectively demands the rapid development of China's financial industry and further provides a basis for the 
development of marine economy.

Guiding financial capital to support the development of marine economy is of great significance for speeding up the construction of the 21st-Century Maritime Silk Road and enhancing the comprehensive national strength. An et al. (2014) find that the improvement of financial development of the four provinces in Bohai Rim will invariably drive the development of local marine economy. [6] Wang and Yao (2016) conduct empirical research based on coastal area panel data, and the results show that financial development is currently an important factor in driving the China's marine economy. [7] Xing et al. (2016) studied the relationship between financial development and the optimization of marine industrial structure of 11 coastal provinces in China. The empirical results show that the development trend and coupling relationship in most of these places are showing a steady upward trend. [8] However, Sun et al. (2017) conduct research based on two-stage least squares and threshold regression, the empirical results show that there is still a phenomenon of "financial repression" in the process of marine economic development in China. [9]

The existing literature provides the basis for this paper to study the impact mechanism of financial development on regional marine economy, but there are still some shortcomings. The existing researches are mostly based on traditional econometric models, assuming that the economic variables are irrelevant among regions, which is inconsistent with reality. In this paper, the Spatial Durbin Model (SDM) is introduced into the analysis framework, and the spatial spillover effects of financial development on regional marine economic growth is analyzed in depth, in order to provide a reference for the financial support for the development of marine economy.

\section{Method and Data}

According to "The First Law of Geography" proposed by Tobler (1970), everything is related to everything else, but near things are more related than distant things. [10] Taking into account the spatial correlation of the marine economy, this paper uses Spatial Durbin Model (SDM) for empirical analysis.

$$
\left.d_{i j}=6378 \times \operatorname{acos}\left\{\sin \left(\text { lat }_{i} \times \frac{\pi}{180}\right) \times \sin \left(\text { lat }_{j} \times \frac{\pi}{180}\right)+\cos \left(\text { lat }_{i} \times \frac{\pi}{180}\right) \times \cos \left(\text { lat }_{j} \times \frac{\pi}{180}\right) \times \cos \left[\text { long }_{i}-\text { long }_{j}\right) \times \frac{\pi}{180}\right]\right\}
$$

where $\operatorname{lat}_{i}$ and $\operatorname{long}_{i}$ represent the latitude and longitude of the region $i$, respectively.

\subsubsection{Local Moran'I Test}

The Global Moran'I test examines the spatial correlation of the observed variables in the whole space. To examine the spatial correlation among the regions, a Local Moran'I test is required.

$$
\mathrm{I}_{i}=\frac{\left(x_{i}-\bar{x}\right)}{S^{2}} \sum_{j=1}^{n} w_{i j}\left(x_{j}-\bar{x}\right)
$$

Taking the observational variable as the horizontal axis and its spatial lag term as the vertical axis to construct

\subsection{Spatial Correlation Test}

The spatial correlation test is based on statistical analysis of variables to determine whether there are spatially related matrix is not a binary matrix, the common test methods include the Global Moran'I test and the Local Moran'I test (Moran, 1950). [11] Global Moran'I test is used to distinguish whether sample variables have a general spatial correlation, while Local Moran'I test can further clarify the spatial correlation characteristics of sample variables in each region.

\subsubsection{Global Moran'I Test}

The Global Moran'I index generally ranges from [-1, 1]. A Global Moran'I index greater than 0 indicates that the variable has a positive correlation in space, that is, it exhibits a certain spatial agglomeration, while it less than 0 indicates that there is a negative correlation between variables in different regions, that is, a certain spatial exclusion; and the value close to 0 indicates that the spatial correlation of variables is not obvious. The concrete expression of the Global Moran'I index is as in formula (1):

$$
\mathrm{I}=\frac{\sum_{i=1}^{n} \sum_{j=1}^{n} w_{i j}\left(x_{i}-\bar{x}\right)\left(x_{j}-\bar{x}\right)}{S^{2} \sum_{i=1}^{n} \sum_{j=1}^{n} w_{i j}}
$$

where $n$ is the sample size; $x_{i}$ is the observation of variable $x$ in the $i$ region; $\bar{x}$ is the sample mean of variable $x ; S^{2}$ is the sample variance, and $w_{i j}$ is the spatial weight matrix. This paper introduces the inverse distance weight matrix based on the study of Wilhelmsson M. [12], namely:

$$
w_{i j}(d)=\left\{\begin{array}{c}
1 / d_{i j}^{\psi}, i \neq j \\
0, i=j
\end{array}\right.
$$

where parameter $\psi$ measures the speed at which the spatial correlation of variable decreases with distance, and its value is 2 in this paper; $d_{i j}$ is the distance between area $\mathrm{i}$ and $\mathrm{j}$. It can be calculated according to the provincial latitude and longitude of the provincial capitals: characteristics between variables. When the spatial weight coordinate system, a Moran'I scatter plot can be drawn. If the Local Moran'I index is significantly positive, then the observations are distributed in the first quadrant ( $\mathrm{H}-\mathrm{H}$ spatial correlation model) and the third quadrant (L-L spatial correlation model); if the local Moran'I index is significantly negative, then the observations distribution in the second quadrant (L-H spatial association mode) and the fourth quadrant (H-L spatial association mode).

\subsection{Panel SDM Method}

\subsubsection{Construct Econometric Model}

Based on the traditional panel data model, the spatial 
weight matrix is introduced using the study of Lasage and Pace to establish the panel SDM:

$$
\mathrm{y}=\alpha I_{n}+\rho W y+\beta X+\theta W X+\varepsilon
$$

where y is explained variable and $X$ are explanatory variables with other control variables. $\alpha$ is a constant term, and $\beta$ and $\theta$ are estimated coefficients of $X$ and $W X . I_{n}$ is an $n \times 1$ order unit matrix, and $n$ is the number of cross-section elements, and $\varepsilon$ is an error term. $W$ is spatial weight matrix. $W y$ and $W X$ are the spatial dependence of explained variable and explanatory variable respectively, and $\rho$ is the spatial autoregression coefficient.

It is worth noting that when the autoregression coefficient $\rho$ in formula (5) is not significantly 0 , it means there is a spatial correlation between the explained variables in different regions. Under this circumstance, the marginal effect of $X$ and $W X$ on $y$ is not the parameters $\beta$ and $\theta$. Because $X$ and $W X$ have an effect on $y, y$ in different regions will also interact with each other. In other words, $X$ and $W X$ have indirect effects on $y$, and $\beta$ and $\theta$ cannot directly measure the spatial spillover effect of explanatory variables on explained variable, which needs further decomposition.

\subsubsection{Decomposition of Spatial Spillover Effects Based on Partial Differential}

In order to reasonably explain the regression coefficients of the spatial econometric model, LeSage \& Pace (2009) proposed a partial differential method for spatial regression models. [13]

Rewrite model (5) as follows:

$$
\left(I_{n}-\rho W\right) \mathrm{y}=\alpha I_{n}+\beta X+\theta W X+\varepsilon
$$

Assume that matrix $X$ contains $K$ variables, and note that the $r^{\text {th }}$ variable is $x_{r}=\left(x_{1 r} x_{2 r} \ldots x_{n r}\right)^{T}$, then there are:

$$
\begin{gathered}
\beta X=\sum_{r=1}^{K} \beta_{r} x_{r} \\
\theta W X=\sum_{r=1}^{K} \theta_{r} W x_{r}
\end{gathered}
$$

Therefore, model (6) can be rewritten as:

$$
\mathrm{y}=\left(I_{n}-\rho W\right)^{-1} \alpha I_{n}+\left(I_{n}-\rho W\right)^{-1} \sum_{r=1}^{K} \beta_{r} x_{r}+\left(I_{n}-\rho W\right)^{-1} \sum_{r=1}^{K} \theta_{r} W x_{r}+\left(I_{n}-\rho W\right)^{-1} \varepsilon
$$

Make:

$$
\begin{gathered}
\mathrm{V}(\mathrm{W})=\left(I_{n}-\rho W\right)^{-1}=I_{n}+\rho W+\rho^{2} W^{2}+\rho^{3} W^{3}+\cdots \\
S_{r}(\mathrm{~W})=\mathrm{V}(\mathrm{W})\left(I_{n} \beta_{r}+\theta_{r} W\right)
\end{gathered}
$$

$$
y=\sum_{r=1}^{K} S_{r}(\mathrm{~W}) x_{r}+\mathrm{V}(\mathrm{W}) \alpha I_{n}+\mathrm{V}(\mathrm{W}) \varepsilon
$$

To explain the role of $S_{r}(W)$, expand the model (12) to the following matrix form:

Then:

$$
\left(\begin{array}{c}
y_{1} \\
y_{2} \\
\vdots \\
y_{n}
\end{array}\right)=\sum_{r=1}^{K}\left(\begin{array}{cccc}
S_{r}(\mathrm{~W})_{11} & S_{r}(\mathrm{~W})_{12} & \cdots & S_{r}(\mathrm{~W})_{1 n} \\
S_{r}(\mathrm{~W})_{21} & S_{r}(\mathrm{~W})_{22} & \cdots & S_{r}(\mathrm{~W})_{2 n} \\
\vdots & \vdots & \ddots & \vdots \\
S_{r}(\mathrm{~W})_{n 1} & S_{r}(\mathrm{~W})_{n 2} & \cdots & S_{r}(\mathrm{~W})_{n n}
\end{array}\right)\left(\begin{array}{c}
x_{1 r} \\
x_{2 r} \\
\vdots \\
x_{n r}
\end{array}\right)+\mathrm{V}(\mathrm{W}) \alpha I_{n}+\mathrm{V}(\mathrm{W}) \varepsilon
$$

The $\mathrm{y}_{\mathrm{i}}$ of one of the region $i(i=1,2, \ldots, n)$ can be expressed as:

$$
y_{i}=\sum_{r=1}^{K} S_{r}(\mathrm{~W})_{i 1} x_{1 r}+S_{r}(\mathrm{~W})_{i 2} x_{2 r}+\cdots+S_{r}(\mathrm{~W})_{i n} x_{n r}+\mathrm{V}(\mathrm{W})_{i} \alpha I_{n}+\mathrm{V}(\mathrm{W})_{i} \varepsilon
$$

According to formula (14), taking the partial derivative of $x_{i r}$, the $r^{\text {th }}$ explanatory variable in this region yields formula (15); taking the partial derivative of $x_{j r}$, the $r^{\text {th }}$ explanatory variable in the other region $j$ yields formula (16):

$$
\begin{aligned}
\frac{\partial y_{i}}{\partial x_{i r}} & =S_{r}(\mathrm{~W})_{i i} \\
\frac{\partial y_{i}}{\partial x_{j r}} & =S_{r}(\mathrm{~W})_{i j}
\end{aligned}
$$

Among them, $S_{r}(W)_{i i}$ measures the influence of the $r^{\text {th }}$ explanatory variable in region $i$ on the explained variables in this region, ie, the direct effect. $S_{r}(W)_{i j}$ measures the influence of the $r^{\text {th }}$ explanatory variable in region $j$ on the explained variables in region $i$, ie indirect effects.

\subsection{Data}

This paper studies the impact of financial development on marine economy in 11 coastal provinces (including Tianjin, Hebei, Liaoning, Shanghai, Jiangsu, Zhejiang,
Fujian, Shandong, Guangdong, Guangxi, and Hainan) in China.

1. Explained variable. The proportion that GOP (Gross Ocean Production) in GDP in the coastal areas, that is, the relative value of gross ocean production (RVGOP) is selected as explained variable to measure ocean economic growth in the region.

2. Explanatory variables. The financial factor is an important force to promote the growth of the marine economy. Consistent with most empirical studies, this paper selects FIR (Financial Interrelations Ratio) to measure the overall level of financial development. The calculation is that $\mathrm{FIR}=$ regional total deposits and loans/regional GDP. In addition, in order to refine the relationship between different financing channels and regional marine economy, based on existing studies [14-16], this paper also selects the following indicators:

(1) Intensity of government investment (RVGOV), expressed as the proportion of government investment in GDP in coastal provinces; 
(2) Relative development of insurance market (RVINSU), expressed as the proportion of premiums in GDP;

(3) Relative development of the venture capital market (VC), expressed as the intensity of venture capital in coastal areas.

3. Control variables. Based on the relevant research of Yao (2016) [7], the following control variables were selected:

(1) Relative technological progress of the marine economy (RVMT), which is measured by the ratio of the added value of the ocean scientific research education and management services to GDP;

(2) Industrial structure of marine economy (ES), which is expressed as the proportion of the tertiary industry's output of ocean economy in regional GOP;

(3) Relative development of foreign trade (RETRAD), which is expressed as the proportion of total import and export trade in regional GDP.
The GOP of coastal provinces, the tertiary industry's output of ocean economy, and the added value of the ocean scientific research education and management services comes from "China Ocean Statistical Yearbook"; the deposits and loans in coastal areas come from the Wind database; insurance premium income, regional GDP, regional total import and export, and regional government investment come from the website of the National Bureau of Statistics; the intensity of VC comes from "China Venture Capital Investment Development Report". Taking into account the data consistency, this paper selected data from 2006 to 2014. Since the scale of VC intensity is relatively large, in order to reduce the heteroscedasticity, logarithmization is performed. A minority value of 0 is directly taken as 0 when taking the logarithm.

Substituting the above indicators into model (12), the SDM of this paper is:

$$
\begin{gathered}
R V G O P=S_{1}(W) F I R+S_{2}(W) R V G O V+S_{3}(W) R V I N S U+S_{4}(W) L n V C+S_{5}(W) R V M T \\
+S_{6}(W) E S+S_{7}(W) R E T R A D+V(W) \alpha I_{n}+V(W) \varepsilon
\end{gathered}
$$

The descriptive statistics for the relevant variables are as follows:

Table 1. Descriptive statistics of variables.

\begin{tabular}{llllll}
\hline Variable & Obs & Mean & Std. Dev. & Min & Max \\
\hline RVGOP & 99 & .1792466 & .0902897 & .0523681 & .3772332 \\
FIR & 99 & 2.592276 & .7184378 & 1.518885 & 4.593874 \\
RVGOV & 99 & .1539019 & .054321 & .083718 & .3192636 \\
RVINSU & 99 & 2.392469 & .7210326 & 1.264647 & 5.148905 \\
lnVC & 99 & 7.042585 & 1.493911 & 0 & 9.21034 \\
RVMT & 99 & 2.866663 & 1.985651 & .3058755 & 7.374629 \\
ES & 99 & .4713636 & .0743555 & .313 & .643 \\
RETRAD & 99 & .5744745 & .4207952 & .1096992 & 1.680503 \\
\hline
\end{tabular}

\section{Empirical Analysis}

\subsection{Spatial Autocorrelation Analysis}

First, a global spatial autocorrelation test was performed on the marine economic development of coastal provinces based on the Global Moran'I index. The Global Moran'I index trend of marine economic development from 2006 to 2014 is shown in Figure 1.

Figure 1 shows that the Global Moran'I index of marine economic development in China during 2006-2014 was negative and basically less than -0.4 , indicating that there is a significant spatial autocorrelation in the marine economy of China's coastal provinces, which is manifested as spatial exclusion. The degree of spatial exclusion declined slightly from 2006 to 2009 , and then basically maintaining stability from 2010 to 2014. This phenomenon may be due to excessive competition among several maritime provinces during the sample period. Overall, no scale agglomeration has yet formed. Cooperation between the maritime provinces needs to be strengthened.

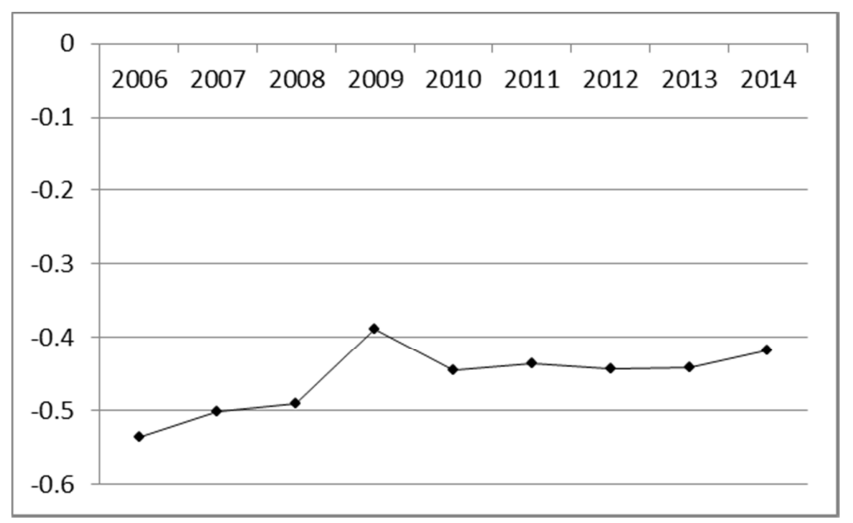

Figure 1. Global Moran'I index of GOP/GDP in 2006-2014.

After the global autocorrelation test, a local spatial autocorrelation test was performed based on the Local Moran'I index. This paper analyzes the spatial correlation characteristics of the marine economy by taking the data from the initial and final period of the sample as the representative, and plots the Moran'I scatter plot as follows: 


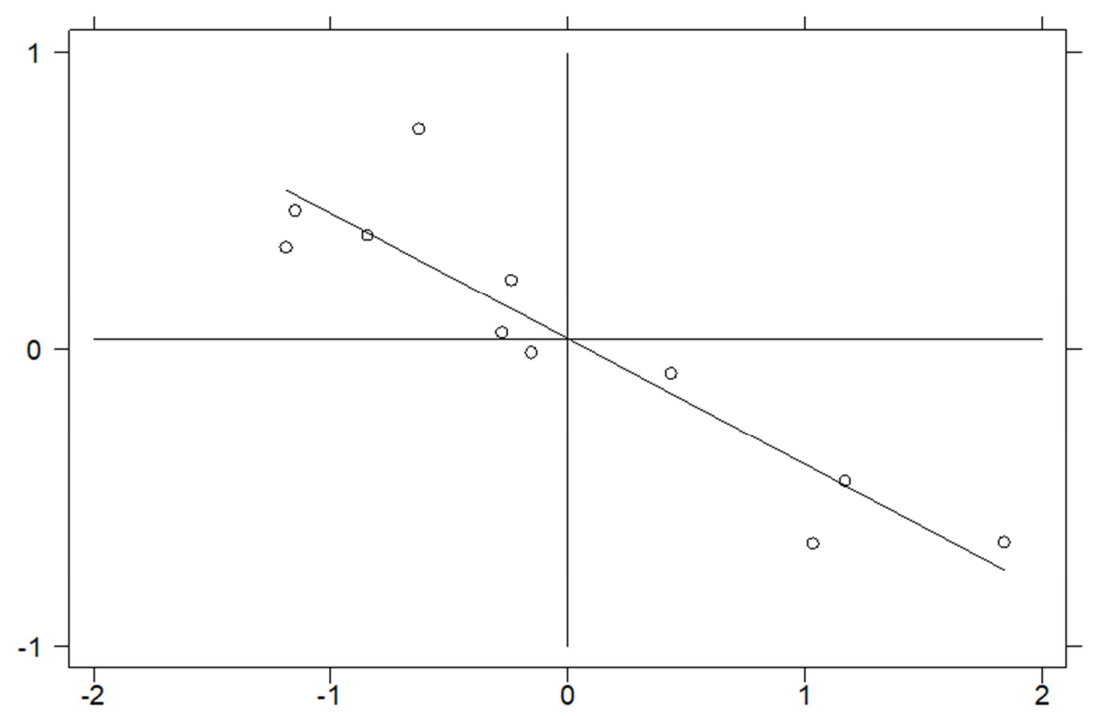

Figure 2. Moran'I scatter plot in 2006.

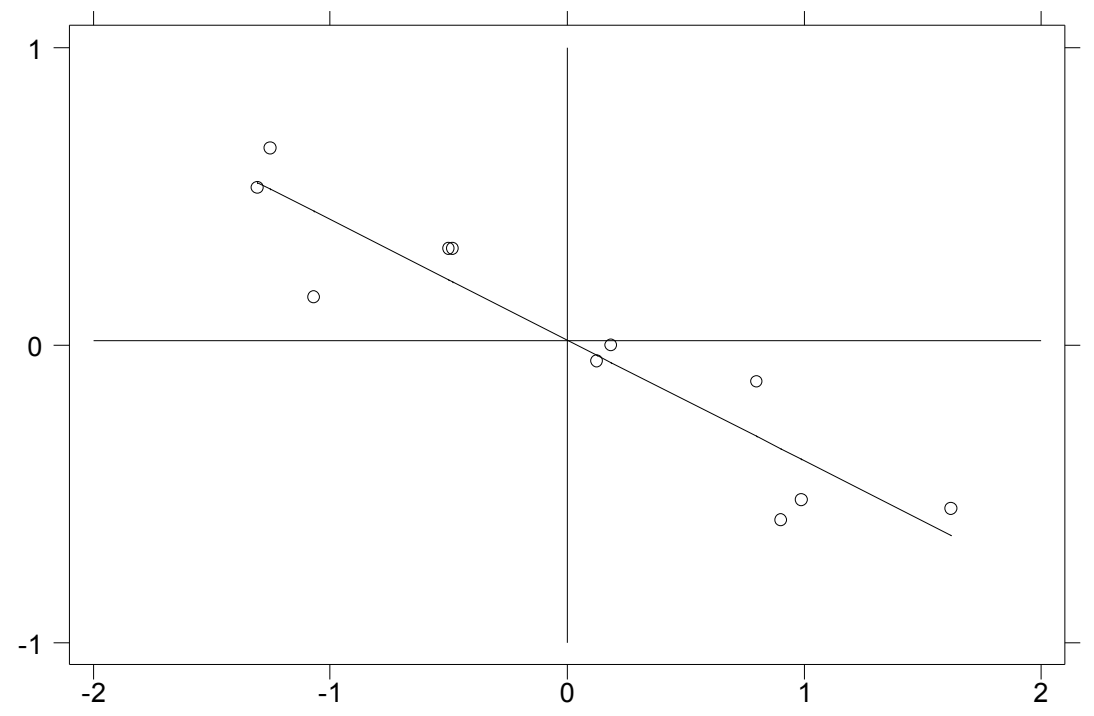

Figure 3. Moran'I scatter plot in 2014.

The horizontal axis of the Moran'I scatter plot is the relative development level of the marine economy and its spatial lag is vertical axis. From Figure 2 and Figure 3, it can be seen that most of the coastal provinces of China are located in the second quadrant ("Low Marine Economic Level - High Spatial Lag" development model) and the fourth quadrant ("High Marine Economic Level - Low Spatial Lag" development model), which presents a significant spatial exclusion. This shows that the development of regional marine economy has caused congestion due to the problems of industrial duplication and other issues. The spatial exclusion of regional marine economy cannot be ignored.
Overall, there is a significant spatial correlation in the development of China's marine economy. When it is studied, spatial characteristics should be considered and spatial econometrics should be used.

\subsection{Results}

This paper analyzes the impact of financial development on the marine economy in 11 coastal provinces in China during 2006-1014 using the Maximum Likelihood Estimation (MLE) based on the Spatial Durbin Model (SDM). The estimated results are shown in Table 2:

Table 2. SDM estimation results.

\begin{tabular}{llll}
\hline \multirow{2}{*}{ Variable } & Random Effects & Fixed Effects \\
\cline { 2 - 4 } & Coef. & P-Value & Coef. \\
\hline$\alpha$ & $0.204 * * *(5.510)$ & 0.000 & - \\
$\rho$ & $-12048 * *(-3.890)$ & 0.000 & $-12787.4 * * *(-4.22)$ \\
FIR & $0.031 * * *(3.420)$ & 0.001 & $0.026 * * *(3.190)$ \\
RVGOV & $-0.266^{* * *(-3.570)}$ & 0.000 & $-0.280 * * *(-3.790)$ \\
\hline
\end{tabular}




\begin{tabular}{llll}
\hline \multirow{2}{*}{ Variable } & Random Effects & & Fixed Effects \\
\cline { 2 - 4 } & Coef. & P-Value & Coef. \\
\hline RVINSU & $0.0001(0.040)$ & 0.970 & $0.001(0.290)$ \\
lnVC & $0.001 *(1.710)$ & 0.087 & $0.001 *(1.950)$ \\
RVMT & $0.016^{* * *(3.390)}$ & 0.001 & $0.010^{* *}(2.170)$ \\
ES & $-0.014 * * *(-1.230)$ & 0.000 & $-0.017 * * *(-1.290)$ \\
RETRAD & $-0.199(-5.450)$ & 0.219 & 0.051 \\
W*FIR & $-804.608^{* * *(-3.000)}$ & 0.003 & $-0.202(-5.890)$ \\
W*RVGOV & $11613.310^{* *}(2.480)$ & 0.013 & $-724.449 * *(-2.270)$ \\
W*RVINSU & $8.082(0.070)$ & 0.945 & $13413.360 * * *(2.870)$ \\
W*lnVC & $-40.241(-0.550)$ & 0.583 & $10.793(0.100)$ \\
W*RVMT & $-518.958^{* * *}(-2.640)$ & 0.008 & $-71.233(-1.030)$ \\
W*ES & $2164.840 * * *(4.090)$ & 0.003 & $-378.042 *(-1.770)$ \\
W*RETRAD & $5484.034 * *(2.920)$ & 0.000 & $2438.840 * *(3.360)$ \\
R2 & 0.7215 & & $5029.660 * * *(2.510)$ \\
Log-likelihood & 287.9342 & & 0.004 \\
Hausman & -34.84 & & 0.922 \\
\hline
\end{tabular}

Note: $*, * *, * *$ are significant at $10 \%, 5 \%$, and $1 \%$ confidence levels, respectively.

From Table 2, it can be seen that the autocorrelation coefficient $\rho$ in the estimation results of random effects and fixed effects are significantly negative at a confidence level of $1 \%$, which indicates that there is a significant spatial exclusion of the explanatory variable, i.e., marine economic development level. The development of the marine economy in the surrounding areas will inhibit the improvement of the local marine economy, which is consistent with the results of spatial autocorrelation test. Since the Hausman statistic is negative, the null hypothesis of random effects cannot be rejected. The following analysis of this paper is based on random effects.

Because there are significant spatial correlations among regions, the regression coefficients of variables in Table 2 cannot directly reflect the impact of related variables on the development of marine economy. Therefore, the effect needs to be decomposed into direct effects and indirect effects. The specific results are shown in Table 3.

Table 3. Effect decomposition (based on random effects model).

\begin{tabular}{|c|c|c|c|c|}
\hline \multirow{2}{*}{ Variable } & \multicolumn{2}{|l|}{ Direct Effects } & \multicolumn{2}{|l|}{ Indirect Effects } \\
\hline & Coef. & P-Value & Coef. & P-Value \\
\hline FIR & $0.038 * * *(3.610)$ & 0.000 & $-0.032 * * *(-3.700)$ & 0.000 \\
\hline RVGOV & $-0.368 * * *(-3.380)$ & 0.001 & $0.410 * * *(2.770)$ & 0.006 \\
\hline RVINSU & $0.001(0.160)$ & 0.874 & $-0.0002(-0.070)$ & 0.947 \\
\hline $\ln V C$ & $0.002 *(1.720)$ & 0.086 & $-0.001(-0.700)$ & 0.483 \\
\hline RVMT & $0.020 * * *(4.060)$ & 0.000 & $-0.019 * * *(-3.710)$ & 0.000 \\
\hline ES & $-0.030 * *(-2.070)$ & 0.038 & $0.065 * * *(4.030)$ & 0.000 \\
\hline
\end{tabular}

Note: $* * *, * * *$ are significant at $10 \%, 5 \%$, and $1 \%$ confidence levels, respectively.

\subsubsection{The Impact of FIR}

The direct effect of FIR on marine economy is 0.038 and it is significant at the confidence level of $1 \%$, which indicates that the local financial development level can effectively promote the development of the local marine economy. With the other conditions remaining unchanged, when the proportion of total deposits and loans in GDP increases by $1 \%$, the proportion of GOP in GDP will increase by $0.038 \%$. Financial development is currently an important factor driving the development of the marine economy, and bank loans are among the most common financial instruments. Up to now, the financing of the global marine industry is still dominated by bank loans. [17] A survey conducted by Fortis Bank shows that in the traditional financing channels, about $80 \%$ external financing of shipping companies comes from bank loans. At present, China's marine finance is still incomplete, and the financing channels of marine companies are relatively single, which further exacerbates their dependence on bank loans.
The indirect effect of FIR on the marine economy is -0.032 and is significant at a $1 \%$ confidence level. It indicates that the increase in FIR in the surrounding areas will lead to a decline in the development of local marine economy, that is, the development of FIR has a negative spatial spillover effect on the marine economy.

\subsubsection{The Impact of Government Investment}

The direct effect of government investment on marine economy is -0.368 and it is significant at the $1 \%$ confidence level. This shows that local government investment has a significant inhibitory effect on the development of local marine economy. Under the premise that other conditions remain unchanged, when the proportion of government investment in GDP increases by $1 \%$, the proportion of GOP in GDP will decrease by $0.368 \%$. The possible reason is that government investment has a certain degree of "crowding-out effect" on other financing channels, which limits the input scale of capital in the development of marine economy. In the future development process, first, the 
government should improve the financial market, especially the development of marine finance, and broaden the financing channels. Second, it should innovate the way that government invests in marine economy, such as establishing the National Ocean Trust Fund and the China Ocean Industry Investment Fund.

Contrary to the direct effect, the indirect effect of government investment is significantly positive at the $1 \%$ confidence level, that is, the government investment in the surrounding areas has a positive spatial spillover effect on the development of the local marine economy.

\subsubsection{The Impact of Insurance Premium Income}

Insurance premium income has a positive direct effect and a negative indirect effect on the development of the marine economy, but neither of them has passed the significance test. The development of the marine economy is characterized by high risks and large investment. As a loss compensation mechanism, insurance can effectively share risks, reduce losses, thus to promote the development of related industries. However, compared with developed countries, China's insurance market is still in its infancy period, and insurance coverage is relatively narrow, which limits the full play of the role of insurance functions and is not conducive to the sustainable development of the marine economy. [3]

\subsubsection{The Impact of $V C$}

The direct effect of venture capital intensity on the marine economy is positive and significant at the $10 \%$ confidence level. However, its elasticity is obviously less than that of FIR and government investment. Its indirect effect is negative and does not pass the significance test. On the one hand, the proportion of direct financing is currently low in the development of China's marine economy, and the structural imbalance of financial markets is obvious; On the other hand, small and medium-sized emerging ocean companies in the initial stage and growth stage are faced with such problems as large natural disasters, uncertain potential earnings, and less effective collateral available for loans, which cannot meet the commercial bank lending requirements, resulting in the marine industry's financing problems and difficult loans. However, venture capital can provide effective financial support for this part of the enterprise and promote its development. At present, China's venture capital funds and other new financing methods are developing slowly, and their role in promoting marine economy cannot be fully realized. It is necessary to further establish and improve the venture capital market mechanism, improve the enterprise information disclosure mechanism and so on.

\subsubsection{The Impact of Control Variables}

The direct effect of marine technological progress on marine economy is significantly positive. The development of marine science and technology can directly stimulate the exploitation and utilization of marine resources, and improve the sustainable development of marine economic. [18] The dependence of marine economy on marine science and technology is increasing gradually, and the driving role of marine technology in marine economy is becoming increasingly prominent. [19] The indirect effect of it is significantly negative, further confirming that there is a spatial exclusion in China's marine economy development. The industrial structure of marine economy and the level of foreign trade have a significant inhibitory effect on the development of regional marine economy, but it has a positive spatial spillover effect of regional marine economy development.

\section{Conclusion}

Based on the partial differential analysis of SDM, this paper uses the provincial panel data of 11 coastal provinces in China from 2006 to 2014 to study the spatial spillover effects of financial development on the marine economy. The empirical results show that:

(1) The marine economic development of 11 coastal provinces in China during 2006-2014 showed significant spatial correlation characteristics, which was specifically manifested as spatial exclusion.

(2) Different financing channels have different influences on the development of marine economy. The FIR has a significant role in promoting the development of regional marine economy, and it has a negative spatial spillover effect on marine economy development in the surrounding regions. In contrast to it, government investment has a certain inhibitory effect on the development of local marine economy but has a positive spatial spillover effect. At the present stage, insurance has not yet shown a significant impact on the development of marine economy. Venture capital can significantly promote the development of local marine economy, but its spatial spillover effect on surrounding area is not obvious.

(3) Technological progress has a significant role in promoting the marine economy. The concrete manifestation of this is that every $1 \%$ increase in marine technology will directly drive the relative development level of local marine economy to increase by $0.02 \%$.

In order to promote the development of marine economy and speed up the construction of marine power, China needs to establish and improve relevant mechanisms, further play the supporting role of financial support and the guiding role of technological progress.

\section{Acknowledgements}

This research was sponsored by China Association of Marine Affairs (CAMA) and Association of Ocean of China (AOC): Research on the Supports of Venture Capital Fund to Marine Economic Development (No. CAMAZD201709).

\section{References}

[1] H. M. Yan, "Know the ocean, develop the ocean and expand the oceanic economy," J. China Population, Resources and Environment. vol. 2. 1992, pp. 17-20. 
[2] F. Cui and S. S. Zhang, "Ocean exploitation and environment risk: the analysis of the Gulf of Mexico oil spill," "Know the ocean, develop the ocean and expand the oceanic economy," A. Annual Meeting of Chinese Sociology and the Second Forum on Marine Sociology, 2011.

[3] J. Zhang, "Financial support to marine economy: problems and their choices," J. Fujian Tribune. vol. 5. 2016, pp. 46-49.

[4] F. Zhang, "Preliminary study on the design of financing mechanism of regional marine industry," D. Ocean University of China. 2009

[5] W. Wang and T. Zhan, "The development of marine finance," J. China Finance. vol. 19. 2016, pp. 57-58.

[6] H. B. An, F. Yang, and B. C. Yang, "Interaction mechanism between financial development and marine economy in economic circle around Bohai Sea," J. Technology Economics. vol. 33. 2014, pp. 109-114.

[7] H. Wang and X. H. Yao, "Technological support and financial support in the development of marine economy: an empirical study based on panel data in coastal areas," J. Shanghai Finance. vol. 9. 2016, pp. 20-26+37.

[8] M. Xing, J. G. Zhang, and W. M. Feng, "Research on coupling development of finance and marine industrial structure optimization in China," J. Resource Development \& Market. vol. 6. 2016, pp. 728-734.

[9] K. Sun, C Zhang, and J. F. Liu, "Has financial agglomeration promoted marine economic efficiency? An empirical study based on IV-2SLS and Threshold Model," J. Resource Development \& Market. vol. 33. 2017, pp. 584-590.

[10] W. Tobler, "A computer movie simulating urban growth in the detroit region," J. Economic Geography. vol. 46. 1970, pp. 234-40.
[11] P. Moran, "Notes on Continuous Stochastic Phenomena," J. Biometrika. vol. 37. 1950, pp. 17-23.

[12] M. Wilhelmsson, "Spatial models in real estate economics," J. Housing, Theory and Society. vol. 19. 2002, pp. 92-101.

[13] J. P. Lesage, and R. K. Pace, "Introduction to Spatial Econometrics," J. Spatial Demography. vol. 1. 2009, pp. 143-5.

[14] X. Zhao and Y. Peng, "The influence mechanism of regional financial development on marine economic growth: with spatial econometric model," J. Chinese Fisheries Economics. vol. 19. 2016, pp. 57-58.

[15] Y. D. Yu and W. X. Lu, "Study on the effects of venture capital on the technological innovation efficiency in China," J. Shanghai Journal of Economics. vol. 8. 2017, pp. 47-60.

[16] X. Chen, D. M. Chen, and S. Q. Xie, "Venture capital, capital account opening and total factor productivity," J. Science Research Management. vol. 4. 2017, pp. 65-75.

[17] D. M. Liu, F. He, C. Y. Zhang, G. Wu, and W. J. Feng, "Maritime finance and China's maritime economy strategy," J. International Economic Review. vol. 5. 2015, pp. 43-56+5.

[18] Z. Y. Wang and F. C. Liu, "Analysis of consistency of marine science and technology innovation ability and marine economy development," J. Science of Science and Management of S. \& T. vol. 32. 2011, pp. 42-47.

[19] H. D. Du, W. Guan, S. Wang, X. B. Liang, "The efficiency of Chinese marine science and technology progress contribution rate: based on Solow and Three-stage DEA Model," J. Ocean Development and Management. vol. 34. 2017, pp. 70-80. 